\title{
Effectiveness of innovative training models in building capacity of frontline health workers to manage Non-communicable diseases. A cross- sectional study in four counties in Kenya
}

Sarah kosgei ( $\square$ sarahchebs@gmail.com )

Amref Health Africa

Colleta Kiilu

Amref Health Africa

Sarah Jefferys

Amref Health Africa

Alice Aiello

Amref Health Africa

Christopher Were

GlaxoSmithKline Research and Development

Bryson Sifuma

Amref Health Africa

George Kimathi

Amref Health Africa

Anastasiah Kimeu

Amref Health Africa

Research article

Keywords:

Posted Date: July 1st, 2019

DOI: https://doi.org/10.21203/rs.2.10823/v1

License: (c) (1) This work is licensed under a Creative Commons Attribution 4.0 International License.

Read Full License 


\section{Abstract}

Objectives This research sought to evaluate the effectiveness of innovative learning approaches in training health workers for effective management and control of diabetes and childhood asthma. Setting Assessment was conducted in Kilifi, Nyeri, Nairobi and Kakamega counties in Kenya in selected subcounties in the 4 counties. Participants Health workforce were randomly selected. Selection was stratified by county and model of training then inflated to account for loss to follow up and 382 participated based on availability and saturation. Interventions Based on high burden of non-communicable diseases (NCDs) specifically Diabetes and asthma in Kenya, AMREF and partners implemented a three-year project (June 2015 - May 2018) aimed at building the capacity of health workers to effectively manage and control the NCDs. It was implemented in 4 counties. The trainings were done using face to face, blended, elearning and mlearning. Primary and secondary outcome measures The research measured the effectiveness of the training models in improving the capacity of health workers to effectively manage and control the NCDs. Results The trainings appreciation rate was $95 \%$ across the four approaches. Health workers were well equipped with skills to address asthma (85.6\%) and diabetes $(94.2 \%)$. Satisfaction though lower in eLearning (64\%) due to reliability of internet and learning platform downtime against mlearning (89\%) and face to face $(90 \%)$, all the training models were found to contribute to improved knowledge. Conclusions The different training models were very effective. The training was successful in increasing knowledge, confidence and commitment to spearhead the preventive and curative aspects of the illnesses. No training model was superior in terms of the degree of satisfaction, improving knowledge, shaping behaviour change and organisational performance. Further research There is need to asses an elearning / mlearning training model that is purely technology based and compare that with the blended approaches of learning.

\section{Strengths And Limitations Of The Study}

- Strength: The model used (Kirkpatrick's model) was able to give step wise information from pre to post training of health workers.

- Limitation 1:The fact that community health workers work on voluntary basis. Some of the reasons for the apathy among those trained through m-learning might be related to the fact that CHVs work on a voluntary basis without a monthly salary among others. It is hard to separate the effect of the roles from the effect of the training delivery method.

- Limitation 2: eLearning was not $100 \%$ online as some of the units was taught face to face especially on the practical on diagnosis of asthma and diabetes. There was some human interaction with all learners whether elearning or mlearning.

\section{Background}

Non-communicable diseases (NCDs) constitute a large group of diseases that are of long duration, and generally slow to progress. Globally, NCDs have become a growing health challenge accounting for a 
large percentage of morbidity and mortality. In 2008 a total of 57 million deaths occurred in the world and $63 \%$ were due to NCDs with nearly $80 \%$ of these NCD deaths (29 million) occurred in low- and middleincome countries(1). Cardiovascular diseases (heart attacks and stroke), cancers, chronic respiratory diseases (chronic obstructed pulmonary disease and asthma (COPD)) and diabetes are responsible for $75 \%(2)$ of NCD-related mortality. The four NCDs share the same set of risk factors: tobacco use, unhealthy diet, harmful alcohol use and physical inactivity. These factors are linked to an increase in preventable morbidity and disability in Sub Saharan Africa, and currently cause more than 36 million deaths annually worldwide. More than a quarter of these deaths - 9 million people - occur before age $60(3)$.

According to the WHO Global status report on NCDs, deaths from NCDs range from $22 \%$ among men and $35 \%$ among women in low-income countries to $8 \%$ among men and $10 \%$ (2) among women in highincome countries. While the traditional understanding of NCDs portrays it as a problem of the old and wealthy, there is a growing reality that the burden of diseases from NCDs lies disproportionately in Low and middle income countries (LMICs). It is projected that by 2020, the largest increase in NCD-related deaths will occur in Africa. By 2030, NCD-related deaths will exceed the combined deaths from communicable diseases, nutritional, maternal and neo-natal deaths by $75 \%(4)$. The human, social and economic consequences of NCDs are felt by all societies and economies, especially in poor and vulnerable populations. Since the first global status report on NCDs (2010) was published, the global agenda on NCDs has progressed. For example, in September 2011, at a United Nations high-level meeting on NCDs, heads of state and government formally recognized these diseases as a major threat to economies and societies and placed them high on the development agenda. In order to translate these commitments into action, in May 2013 the sixty-sixth World Health Assembly adopted the Global action plan for the prevention and control of non-communicable diseases 2013-2020 (known as the Global NCD Action Plan) and a comprehensive global monitoring framework, including a set of nine voluntary global targets and 25 indicators.

\section{Local Health Context}

In Kenya, the burden of NCDs is equally increasing. It accounts for $27 \%$ (5) of deaths mainly among those aged between 30 and 70 years. Prevalence and mortality data is either unavailable or have a high degree of uncertainty due to lack of national NCD information. However, $50 \%$ of all hospital admissions and $55 \%$ of hospital deaths in Kenya are estimated to be due to $\operatorname{NCDs}(6)$, (7). In Kenya like many other developing countries, the major NCDs are cardiovascular conditions, cancers, diabetes, and COPDs with their related sequelae and shared risk factors. Equally contributing to the huge burden of NCDs are violence and injuries particularly traffic accidents, haemoglobinopathies, epilepsy, mental disorders, oral, eye and dental disease.

Amref health Africa and GSK focused their effort in tackling two NCDs, Diabetes and Asthma, in four high prevalence counties in Kenya. The prevalence of type 2 diabetes is increasing with a nationwide prevalence of $4.2 \%$, with an urban and rural prevalence of $10.7 \%$ and $2.7 \%$ respectively(8). In 2012 , 
approximately 17,733 people in Kenya died of diabetes-related causes while 595,400(8) probably remained undiagnosed. The high proportion of undiagnosed cases of diabetes contributes to irreversible complications imposing a huge economic burden on the individual, family, community and health system. Similarly, asthma is estimated to be more prevalent in urban than rural areas. The Ministry of Health indicates that approximately $10 \%$ of the population under 14 years in Kenya has childhood asthma based on the International Study of Asthma and Allergic Disease in Childhood (ISAAC) phase 1 and 3 studies carried out in 1995-2000 in Kenya. During this period, studies indicated that wheezing increased from $17.1 \%$ to $18 \%$ in Nairobi and from $10.4 \%$ to $13 \%(9)$ in Eldoret among $13-14$-year-old children. The prevalence of asthma in older children may also be increasing.

Asthma like diabetes has serious complications if uncontrolled leading to loss of quality of life, low selfesteem which results in reduced social interaction, increased psychosocial trauma, reduced exercise tolerance and which occasionally leads to death(10). In Kenya, there are no population-based studies on asthma prevalence in children below 10 years. A recent report shows that 1 in 10 children aged between 10-14 years are asthmatic(9). This age group forms the nation's future economic development pillar. This age group is at the primary level of Kenya's education pyramid and requires to be well grounded with continuous schooling to progress and mature to productive labour force(11).

Over the years, Kenya's budget allocation for health has been inadequate and the health system therefore faces a huge challenge in addressing the double burden of communicable and non-communicable diseases. Similarly, Health workers have limited skills and resources to competently conduct early detection of diabetes by routinely screening for high blood sugar(12) as well as distinguishing asthma from other COPDs(13). Tutors in pre-service training institutions themselves lack the knowledge and skills in diabetes and childhood asthma management to deliver appropriate content in training courses. Training materials are not regularly updated and standardised to harmonise with health sector guidelines, policies and priorities in management and control of diabetes and asthma. In addition, lack of standardised measures, affect the reporting of asthma, by being lumped with COPDs, which serve to mask the real burden.

Laboratory assessments conducted by Amref Health Africa indicate that most peripheral laboratories are not able to screen for diabetes due to lack of basic equipment and supplies(14). There are also major gaps in collection, handling, testing and referral of blood specimens in these facilities, leading to results of doubtful quality. Ineffective management and control of these NCDs results in persistent/recurrent symptoms which impair the quality of life, contributes to school absenteeism, reduce self-esteem, cause social stigma, increases psychological trauma and occasionally leads to premature death.

Therefore, training of frontline health care workers on management and control of NCDs, is essential to ensuring quality diagnosis, care and treatment for patients with NCDs(15). Health system strengthening including training of health workers is one of the key strategies that are being employed to tackle the burden of NCDs. We assessed the effectiveness of four training delivery approaches: face-to-face, electronic health (eHealth) solutions, mobile health technologies (mHealth) and blended approach on the 
process of identification, diagnosis, management, referral-linkage with facilities, promotion of behaviour change, maintaining records, follow-up and service delivery for diabetes and Asthma. eHealth and mHealth have the potential to improve quality of healthcare by addressing technical shortcomings embedded in health systems(16).

\section{Methods}

Description of intervention and study sites

Based on prevalence of Diabetes and asthma and the challenges of Kenya's health system, Amref Health Africa, in partnership with GSK implemented a three-year project from June 2015-May 2018 to effectively manage childhood asthma and by strengthening the capacity of the health system in Kenya to ensure quality management of diabetes and childhood asthma. The project was implemented in Kilifi, Nairobi, Nyeri and Kakamega counties, purposively selected due to their high prevalence of diabetes and childhood asthma(14). The project utilised a three-Pillar approach: In-service and pre-service training of 2,500 Health Workers; Community-Based Disease Surveillance (CBDS), Mobilisation and Advocacy; Monitoring and Evaluation, Evidence for Policy and Practice Change (Appendix 1). Health workers trained during this three-year project formed the sampling frame of the current assessment of training delivery methods.

\section{Study sites}

The assessment therefore was conducted in selected sub-counties of the four counties. In Nairobi county, the project was study was done in Kasarani and Embakasi; Lurambi and Malava in Kakamega; Kilifi North and Kaloleni in Kilifi and Nyeri Central and Tetu in Nyeri sub-counties.

\section{Study design and data collection}

A cross sectional mixed methods approach comprising qualitative and quantitative techniques was used to determine the effect of different models by examining the levels of knowledge by model of delivery of the intervention. The analysis focuses on comparison between different innovative approaches used in the improvement of knowledge, skills, behaviour and attitudes of the health workers at health facility level and the community health volunteers working in the target communities. In terms of the sequence, both quantitative and qualitative data was collected simultaneously.

\section{Analytical model used for the assessment}

We used Kirkpatrick's model (17) for evaluating effectiveness of training interventions, by assessing the learner's reaction, learning , behavior and organizational performance. Table 1 shows the areas of focus under each level espoused in the model.

Table 1: Levels of assessment using the Kirkpatrick model 


\section{Sampling strategy}

Frontline health workers were randomly selected from a training database maintained by the Amref Health Africa NCDs Project team. Since, this study was not assessing changes on knowledge from baseline to end line, of all participants, a pragmatic sampling process was used; a third of the population (stratified by county and model of training), further inflated by $20 \%$ to account for loss of follow up, was randomly selected (Table 2). A total of 382 health workers were selected for participation in the quantitative survey. There was equal distribution of each category of study participant by model of training across counties to reduce systematic biases. For the qualitative data collection process, a participatory approach involving key actors including the Health management teams at county and sub county level, master trainers, community health volunteers, community elders and community health extension workers, and health care workers (Clinical officers and nurses) at primary care facilities was used. A total of 45 interviews were conducted across sites (Table 2).

\section{Table 2: Number of interviews conducted by type of training model and sites}

\section{Study procedures}

Desk review: Review of various documents on the NCDs project was undertaken to assess the design and the contextual background necessary to generate background understanding of the capacity building for health workers, CHVs and the community to manage NCDs in the four counties. The documents that were reviewed included the project baseline and mid-terms reports, progress reports and other relevant materials generated as part of the Project. The reviews were undertaken during the preparatory phase as an input into the development of the data collection tools.

Patients and Public involvement: - No patient involved - The patients were not recruited for the study as we only assessed the effectiveness of the training methodologies for midlevel health workers and community level workforce trained. However it was good to have the patient in mind. For this research it was important to analyse the outcomes of the trainings because the main aim of the training was to improve diagnosis and management of the mentioned NCDs. The research questions were framed based on the desired outcomes of the clients. Were the clients given the assistance they need when they visit the health facility? Did they get screened and diagnosed as required? The questions went to analyse the competence of the health workers after the training.

\section{Quantitative survey with different trainees involved in the program}

To assess the effect of training on both community and mid-level health workers, structured interviews were conducted with beneficiaries of the training. Trained research assistants were provided with a list of selected participants and interviews were conducted using a short-structured questionnaire programmed using the Open Data Kit (ODK). The two (facility level and community level) questionnaires were used to assess the knowledge levels, reaction, learning and the behavior of health workers in relation to the mode of training that was adopted. 
Interview guides were developed to guide qualitative data collection with key informants. Study participants were purposively identified based on their experiences with the project activities. These were interviewed in languages they understand and in venues convenient to them. Trained research assistants using an interview guide conducted key informant interviews. Interview discussions explored role of context in influencing the project outcomes. In depth Interview (IDIs) explored, what worked best (for whom, in what ways, and in what circumstances)? and any unintended outcomes (positive and negative). The interviews were audio-recorded and later transcribed verbatim with consent from participants.

\section{Data Processing and Analysis}

Quantitative data from the questionnaire were uploaded to a server every day after the interviews for archiving. This data was checked for inaccuracies and inconsistency daily. Verification, cleaning and analysis was conducted using STATA 14(Stata Corp, College Station, Texas, USA). Key indicators from the structured questionnaire were used to examine the difference between the three models using chi square test.

Qualitative data from key informant interviews were audio recorded where possible, transcribed using MS word software. Debriefing sessions were held by the research team lead, the supervisor and the research assistants daily to provide an overview of issues raised. Informal analysis was conducted, and summaries of the collected data made after each session for clarification or follow-up. Both the transcripts and the notes made during the interviews were managed using NVIVO 10 Software (QSR international). Preliminary analysis entailed open coding and progressive categorization of issues based on inductive (where analytical categories are derived gradually from the data) and deductive approaches (where ideas from the interview guide shape the coding scheme) These categories/themes were further refined as understanding from the data evolve. Themes derived from the data were analyzed through the development of analysis charts.

Both verbal and written consent were sought for all interviews. As far as possible, data collection was planned around the respondent's routine activities to minimize disruption. The aim and processes to be followed was explained to all participants as appropriate and their informed consent obtained for participation and for the recording of interviews where applicable. In all cases, number tags were used to anonymize data at the point of collection and reporting when using quotes.

\section{Results}

Characteristics of clients interviewed

Findings are based on interviews conducted with 382 respondents. In total 318 were Frontline health workers and 64 were community level health workers (CHEWs \& CHVs). A total of 93 were interviewed from Kilifi, 97 from Nyeri, 102 from Kakamega and 90 from Nairobi. Table 3 presents the respondents 
demographic characteristics from 382 respondents whose data was available for analysis. The majority $(75 \%)$ of the respondents were female; $83 \%$ were $\mathrm{CHV}$ and $68 \%$ were frontline health workers. Majority (82\%) were in the middle of their career and aged below 50 years. In terms of professional qualification, $67 \%$ of the respondents were midlevel health workers comprising clinical officers, nurses, laboratory technologists, pharmacists and nutritionist and community extension health workers (CHEWs). Of those that reported as $\mathrm{CHV}$, only 2 had nursing experience. Table 3 below shows the characteristics of the clients interviewed.

\section{Table 3: Characteristics of clients interviewed}

Examining role of various actors in the management of NCDs

The study participants were asked to discuss their role in managing NCDs at various levels. At community level, $\mathrm{CHV}$ reported that their role was largely community level education, facilitating referral, follow up and ensuring clients adhere to the treatment given as several CHVs pointed out:

" $R$ : My role is to ensure those suffering from any of the disease they get treatment and they adhere to it because these kinds of diseases you need to be followed up. We emphasize to them that they should adhere to taking their drugs and the situation they are in they should accept it. Because something like diabetes you need to keep on checking yourself regularly" IDI, CHV, site 2

" $R$ : We advise them to seek treatment and we refer them to the hospital for better management, because for us we do not treat, that is the doctors work and they are advised on what to do and which treatment they should get" IDI, CHV, site 4

"R: Creating awareness to the community and specifically on health, for you to attain that you have to take the initiative as a CHV to visit the people in their households to follow up on their health, one they need shelter that is a place to live in, to have a means where they are able to take care of their needs maybe a business or to be employed, they also need to take care of their hygiene, need to have a toilet. For me as a CHV, the training I have from both AMREF and others before AMREF came, they used to tell us to insist to people maybe you are pregnant, you are asthmatic, or you have malaria or maybe they have high blood pressure, you advise them to seek advice and treatment from the hospital. We used to have referral forms but after some time we were never supplied with them again, so for now it is up to you as the CHV to go and visit the client in their households and advise them that the situation they are in either, diabetic or pregnancy they need to go to the hospital for treatment, when they decide to come to the facility I make a call and request one of the care frontline health workers to take care or assist the client I have sent or referred and we communicate with them" IDI, CHV, site 1

"Okay we go to our households, identify, when you identify you refer because that is our work I identify, and I refer. I am not a doctor to treat.... So When I refer the client to our facility she goes there or he goes and receive treatment. When she comes back to the community now my work is to follow up and if she 
has a question which I'm able to answer I can answer if I am not able to answer I refer her back. I refer the client back because some questions are beyond us: IDI, CHV, site 2.

CHV also implement advocacy, through community platform and includes the youth as well

"Okay, like when I was taught eh....You go may be you collect some youths eh...and then whatever I was taught I will bring to them, to my community. I go to women groups, to Barraza's...yeah" CHV 2 site 1

At managerial level, different actors reported that some coordinate the NCDS activities in the county and mobilise resources to support the programs, health education and promotion at different levels as well as supervision. " $R$ : My role majorly is on health education promotion whereby we train the community health work force volunteers and the chiefs and the so as to carry out prevention, and also do screening so that they identify cases on time and they are able to bring them for treatment and also the other issue is that we do a lot of training on all the NCD generally not just diabetes and asthma, but we are doing for all the NCDS"IDI, NCD-Focal person, Site 2

"What we is advocating for, we are liaising with the pharmacy to ensure the commodities are available and we want to thank our pharmacy department he is doing good work. They have really stocked what we wanted. When we came from the training some stocks were not there, like the inhalers but now they're there in plenty. Two, on issues of policy and gate level I can't say anything but one good thing with HMT in case we want anything, we propose and then it is implemented" IDI, Mid-level manager, site 3

Reaction to the training and Learning

In accordance with the Kirkpatrick model, we explored the degree to which participants found the training favourable, engaging and relevant to their jobs. The analysis shows that there were varied opinions in terms of perceived competence and acquisition of skills and competencies in the management of these conditions. For instance, only $51 \%$ of those trained through Mlearning and $57 \%$ of those attending face to face training, indicated they could correctly identify types of diabetes caused by insulin resistance and a drop in the amount of insulin produced by pancreas. When comparing $\mathrm{CHV}$ and frontline health workers, $60.7 \%$ of the $\mathrm{CHV}$ and $61.4 \%$ of the frontline health workers correctly identified the types of diabetes with no differences between the groups.

Depending on the model of training, the process was engaging and allowed learners flexibility on when they can learn and also provided support to the learning. In terms of value of training, most study participants across counties noted that the training regardless of approach was able provide them with skills to influence service delivery as pointed out below.

"R: It was very good, sometimes I would answer the questions while attending my daily duties like cooking and sleeping so I miss them a lot. We started from topic one and now we are in topic four we were even asking them why they have not brought for us the other topics" IDI, CHV, site 1 
"The value of the training? I think I had said earlier maybe I can put it in another way. This is one of the best trainings that our staff needs to get. So it is one of the needed training in our facilities. If one has to control NCD, you see when you staged this in XXXX, you just passed a forest and I have discovered the weather here changes, it follows the pattern in the whole country but one challenge l've noticed here, when there is pollination. It's not only pollination from maize, crops...there is also pollination from the forest in fact you can hear so many people coughing right now. So the air is pollinated with so many different perfumes so you'll expect more patients to come also for asthma. And then the issue of diabetes we made a follow up to know why there are so many diabetic cases and we have involved the nutritionist. The problem here is lifestyle of people here. The lifestyle is wanting. You know this is a sugar cane planting zone, people, their lifestyle is not good. There are so many alcoholics. There are so many people who are misusing foods. They are not using food in the right way. They depend so much on ugali here. They eat the junk food. There is a lot of junk food, people stay several hours without eating like the bodabodas and then they take soda or they take sugar cane. So at the end of the day they will develop such related diabetic cases" IDI, Manager, site 3

\section{Effects of training}

The participants discussed positive aspects of the training ranging from satisfaction and improved knowledge in identifying the symptoms for the conditions especially among CHVs. County level managers also pointed that the training had an impact on $\mathrm{CHV}$ in disease recognition and need for seeking medical care as a coordinator noted:

" $R$ : In those area where training has been done, because I think you have done your own assessment ... and you have seen like I was discussing with some CHVs and she said she was happy she was referring more patient, meaning that patient are now realizing if I have the following signs and symptoms should go for a check-up because it might be diabetes which before they didn't know and once they know the effect of the disease they will actually be feeling that I need to know early to avoid complication so I think it is very wise" IDI, NCD Coordinator, site 2

Another perceived effect was on community referral linkages with some noting this has been strengthened while facilities have set up clinic days to focus on the NCDs:

"R: The clients are very happy we have also had more clinics because I remember more of our rural facilities never used to have clinics especially for diabetes but now that people are trained they are able to come up with the clinics and especially when you go to our rural facilities now because of those training they are able to start clinic days for diabetes and also the community linkage to the facilities have improved because like I said we link them with support group so you can see in some areas we have those group that are linked to every facilities we are able to know actually who is a patient and we are able to follow them right to the community and they are able to visit one another so that is also, even when it comes to issue of supporting one another in terms of foot care and the rest, you find that they are able to know who is who and where they are and even when the client is not coming to the facility they 
are able to make a follow up and know why that client has not come during their clinic day" NCD Focal person, site 1 .

Qualitative interviews also show that the training improved $\mathrm{CHV}$ ability to communicate and debunked myths around NCD as indicated below:

" $R$ : Communication skills, how to engage the community either in a group or individually, the other one is the elearning it has helped us in that, we also used to have patient within the community and we didn't know about the symptoms and we didn't know how to help them and so we used to live with them yet the person is suffering, so in our community we used to believe that the person has been bewitched but the skills we got from AMREF that we visit them and share the information that we got through the phone it has really helped. And we would like for them to be improved through the refresher courses because the training that we got has been a long time ago, we are requesting if you can give us refresher course and if there is anything they can add on to we will be grateful. But the skills they gave us as per now they have really helped us" IDI, CHV, site 4

Other evidence of the effect of training was illustrated through a discussion with $\mathrm{CHV}$ who pointed the improved level of knowledge;

" $R$ : On diabetes we used to think when you have a chronic sore you cannot put on shoes and we also believed if you put on socks the sore will enlarge but through the training we learnt that such a client need to bathe his feet with warm water and clean well in between the toes and wipe them with a clean towel and to use socks that can suck the moisture brought about by heat or sweat and to put on a shoe that is flexible, not too loose or too tight and can be tied using a shoe lace, we thought such a thing is not possible for someone who has such a condition, but know we know what to share with diabetic people. There others who are diabetic and still smokes and drinks alcohol those are some of things we have share with them that if they continue doing that it will deteriorate their condition, those are some of the things I learnt' IDI, CHV, site 1

For CHVS training benefitted the community since most of them were able to take the knowledge back to the community. Frontline frontline health workers also gained skills in classification of clients who come in for asthma:

"We agreed... we were trained in a mixture of nurses, doctors and clinical officers, our major request to all was to make sure the outpatient department is having diabetic, asthma training clinical officer always on duty so that there is proper diagnosis of asthma. Once the diagnosis is made there is a classification. They classify whether this patient is mild, moderate, severe...if it is severe they admit here. Now in the ward here am trained in asthma management. Now the telling lands in my hands and I have done OJD to the staff on how even to use nebulizers to use all those things to make sure" IDI , Front line provider, site 1

While others reported effective referral to higher level facilities when they cannot manage it due to scarcity of the commodities or structural challenges to maintain adequate supply chain system: 
"We ... we get referrals but we have also trained staff in the health centres on the case management of asthma. So they Know those cases to refer here, they refer without wasting time. But also we have stocked commodities in the same facilities related to proper asthma management and the only issues on diabetes... because many of them are not having fridges to keep like...eemm...insulin. They are having fridges for keeping tissues. So but the, in case they identify a diabetic case, they should refer to our county hospital here" IDI, frontline provider, site 4.

The skills from the training enabled frontline health workers and $\mathrm{CHV}$ alike to have confidence in managing the condition: "The value of training is that it gives you the confidence when you get the chance...err. Mmhh just as I said first, with such people, approach is very important" IDI, CHV, site 2

From the provider perspectives, training was able to empower them, and they were appreciative of the process. Quantitative results show that there were no differences among the respondents based on the mode of training in terms of the level of knowledge on diabetes and asthma. There was high level of knowledge regarding symptoms of diabetes and asthma among respondents trained trough different approaches. Only $48 \%$ of those who received training through face to face reported that post-partum care visit can be used for diabetes education prevention, compared to $87 \%$ of those trained through E-learning. Overall, the respondents were knowledgeable of symptoms associated with diabetes, irrespective of the mode of training. These results also indicated that the Learning aspect i.e. the degree to which participants acquire the intended knowledge, skills, attitude, confidence and commitment based on their participation in the training was largely achieved by each model of training with no differences between the groups as indicated on table 4.

\section{Table 4: Knowledge levels on Diabetes}

Table 5 shows that close to $90 \%$ of the respondents trained using different approaches correctly reported that Asthma is not a communicable disease. In addition, majority of the respondents disagreed with the statement that Asthma predominantly affect female children, although $20 \%$ of those trained through Elearning and $17 \%$ trained through M-learning agreed with the statement $p<0.001$. Majority $(69 \%)$ of those trained through E-learning agreed with the statement that physical activity can trigger asthmatic attack in children, compared to $62 \%$ trained through face to face and $52 \%$ trained through M-learning. There were differences between groups on those who reported as true that Asthma is caused by a swelling of the lung with nearly half reporting as positive. In another instance, $53 \%$ of those trained through M-learning noted that exercise and upper respiratory infections can trigger acute asthma attack compared to $81 \%$ and $74 \%$ trained through face to face and E-learning respectively.

\section{Table 5: Knowledge levels on Asthma}

Qualitative results also confirm that the training had an effect on how frontline frontline health workers are managing asthma and the improved community awareness of the condition: "The training has affected in a positive way not a negative way. One, it has made the community to be aware that asthma is another challenge that is facing our people. You know when we are teaching them, we teach them ten 
percent of the relevant population is asthmatic. So when we say that, that message echoes with them. You know people want to hear what is disturbing them. So even as we make them, many of them to attend, if you visit our outpatient, you will see so many patients. Especially this time of the bad weather and many of them they are having halfway knowledge about asthma, halfway knowledge about diabetes. Because it has made the people themselves even to ask more. There was an MCA who came here asking that his people must be told of asthma he has heard it being discussed somewhere. So meaning that something is happening in the community just after this training to make even an MCA to overhear it somewhere and then ends up coming asking, can you send some people to teach my people" IDI, Mid-level manger, site 2

Understanding Behavior change and organizational performance

We examined the degree to which participants apply what they learned during training when they are back on the job and the organizational performance that occur because of the training and the support and accountability package. Secondly, we also examined required Drivers- processes and systems that reinforce, encourage and reward performance of critical behaviors on the job.

Post training experience shows that there was a high rate of agreement of all the post training aspects asked. There were also no differences between the groups in all aspects examined except those who reported the way they managed asthmatic and diabetic patients before the training has not changed with low percentages of between $12 \%$ and $20 \%$ across the groups. Regarding post training experience, the respondents felt they were well equipped with skills to address childhood asthma or diabetes 85.6 and $94.2 \%$ respectively. Nearly $96 \%$ also reported they can teach their colleagues what they learnt as shown in table 6 below.

Table 6: Perception of post training experience

All the study participants reported that they were able to utilise the skills they acquired given that the NCDs in question were largely neglected;

"R: Of course, yes because as a CHV there is the knowledge we had gotten from other previous training but still the community still believed it was being caused by witchcraft. Even asthma they used to believe it is something they have inherited from our ancestors, so they didn't even see the need of seeking treatment and they used to take it as something that is part of their family, so eventually they would die because they never sought treatment. Through the training and staying with the community, we usually attend the chief baraza and we request him to give us a few minutes to talk to the community about the disease and it is something they can seek treatment and be treated and get cured. IDI, CHV, site 3

There was an observation that the main drivers that worked against the effective reward of positive behaviours after the training were largely health system factors. Despite the improvement associated with training, several health system challenges may inhibit continuity of service delivery for the NCDs. For example, lack of tools to monitor progress was reported as a barrier to identifying the real burden as was 
reported "R: For asthma the biggest challenge is that we don't have a...reporting tools for asthma and also with diabetes and hypertension, in fact it is only now that the national government has developed a tool which I was lucky to see but has not yet also been launched, but at least now there is going to be a proper recording, so I want to believe because of lack of proper registers like for asthma, diabetes there many cases which are not reported but they are being seen"IDI, NCD -coordinator, site 2

It was also observed that the challenge of human resource constraints is affecting the sector. One respondent reported that: " $R$ : As much as you would like that person to remain there in the clinic and not do anything else it is almost impossible because of the inadequate workforce" IDI, NCD coordinator, site 3

" $R$ : Human resources it is something that has been a challenge like for the medical officer they are few so in one clinic we may get over 70 patients so managing all those 70 patient at a go with one medical officer sometimes it becomes a challenge, so most of the time we have been using two officers and may be if we get a clinical officer, we had a clinical officer who was attached to the clinic but now he went for further studies so now whoever is off or something we request them to come to the clinic so that they can help the doctors to see the patients" IDI, front line provider, site 2

There are also challenges of supply of commodities such as diagnostics and the cost associated with the drugs and supplies that might negate the efforts made for NCDs " $R$ : The other challenge we have is the commodities, commodities for NCDS it is a very big challenge because again I will come back to the programs like the HIV, Malaria, T.B program we get support from the global funding program so all patients visiting our clinic for HIV services, they get them free" NCD-Coordinator, site 4

Additionally, the funding challenge and the fact that communities still believe that once you get the diseases it is like death sentence makes it hard for example to convince to seek care promptly. The process of referral to the facility for care is also affected by lack of referral booklets affecting documentation of care. Availability of referral booklets will facilitate follow up by $\mathrm{CHVs}$. "R: One major challenge is a gap in the referral between the community and the facility, we cannot say they are not there, we have limited supply of referral booklets that are given to the CHVs in event they get a person with a condition that is closely related to asthma and diabetic they can actually refer. But what they do they actually take verbal or oral referral which sometimes it is not that effective because by the time the patient comes to the hospital there is no guarantee that she or he has been taken care of or has been seen by a clinician" IDI, CHV, site 1

Another challenge is lack of space for the NCDs patients while in some facilities, the infrastructure may not support free movement of clients when they are being treated as clinicians reported " like for instance you come and see mothers have the $\mathrm{MCH}$, TB have their TB clinic but these guys when they come they enrol as general patient at least having one common group for them it will be easier and having a clinic in all the facility having a special clinic for them to be attended to. Like for instance we look at xxxx we have only one facility that has a clinic day, others they just come any other day, sometimes you come there is only one clinician who is to attend all the patient around and has to look at you, and this is a patient who cannot withstand long time at the queue, so most of them prefer to go to the private which is so hard now 
to trace because the private facilities are not attached to the CHVS, so it hard to trace them how far they have gone with the treatment. IDI, Focal person, site 3

At the community level, financial limitations to seek care and means that referred clients will not be able to access services. CHV demotivation from comments made by some members who don't appreciate the role they play in household visits as one pointed out: "R: One of the challenge that I go through and specifically when doing follow up and maybe I have gone to visit him after two or three weeks and they tell you that they think you are idle because you keep on going around visiting people it seems you are being paid a lot of money or you need to get something meaningful to do, if you are not being paid you wouldn't be coming here now and then to keep on telling us to go to the hospital if we are feeling or if we are having such and such symptoms, to us CHVs it is a challenge, sometimes what we go through when we are doing our duties it is very tough and sometimes I feel like giving up or I am tired but I encourage myself not to give up and pray to God that one day he will remember me and also the community to change their perspective so that we can be like the other communities are living. So for me one of the main challenge is being told that you are being paid yet you know it is a volunteer thing you are doing and the only time you get something is when we have a seminar or a meeting at that time we are given five hundred and I have left my business and I have a family that is looking up to me. Sometimes we want to include in our reports that we want to be paid something maybe one thousand at the end of the month, but we don't do that, we just comment and say we are grateful" IDI, CHV, site 1

Despite the organisational challenges described above, some reported that support supervision and issuance of supplies are two main ways in which the front-line provider get support beyond the training. Secondly, in terms of budgeting for NCD, it was reported that there was increase of allocation of budgets for NCDs and structures which may facilitate continuity of improving care for NCDs. Finally in terms of support, respondents discussed the strengthening of outreaches where the health workers are involved to go out and carry out some of the activities with the support of the facility level or the county or sub county level as a critical element of support. This helps them to put that knowledge to practice. Additionally, the mention of a conducive environment for them so that if its infrastructure then at the hospital level, funds for their monthly expenditure was noted as a manager noted "So part of the monies then is geared towards actual lab services, pharmacy. Even as we buy drugs at the county level the hospitals are able to buy drugs at their hospital level. The dispensaries get some money, the health centers get some money so there is a bit of that happening at the level where if you don't have a blood pressure machine, the facility does not wait for the county. If you are given ninety thousand in a quarter then you are able to slot some of that money to buy thermometers, to buy yourself the BP machines" IDI, Manager, site 3

The discussants were able to identify that the training was useful in ensuring they can continue providing services to the clients as one CHV noted:

" $R$ : It will be of help because in my community it is not easy for someone to get this kind of disease because even if it is my child I know how to protect them from asthma, so it has helped me and will 
Frontline health workers on the other hand noted the long term effect of the training was local management of condition that they were previously referring; " $R$ : Before we used to refer them to XXX for the services or treat them and give them drugs and advise them on where to get specialized care and because we didn't have the knowledge and skills then we would refer them to XXXX clinic just like the one we want to start here, before it used to be a burden to us because when a client comes in instead of referring them to XXXX where they have people who are trained like the MO or CO we have people who are trained and they are able to handle at least we are happy we know what we are doing" IDI, Facility in charge, site 3

The progressive effect was also described in the context of reducing complications as some noted; " $R$ : It has decreased because looking at the NCDs, the clients who has been diagnosed with diabetes and it is because of the management you can see the complications they have reduced" IDI, NCD coordinator, site 4. While there was less frequent attack among cases of asthma or number of cases reducing as indicated below: " $R$ : In the last three years after the inception of AMREF the cases are a bit coming down, from what we are seeing from the hospital side, like the number of cases that are being reported nowadays, is not as high as it is, maybe one would say the community are empowered early enough in management so they do not have time to come to the hospital for checkups, there so many factors that attribute to it. From the look of things from the hospital point of view is that cases are decreasing" IDI, Focal person, site 4

Continuity was considered through developing newer strategies to manage the condition both at management and facility level. Streamlining the drugs for the NCD resulted to increased number of patients coming " .... but after the training we started stocking from KEMSA, so when they know medicine is available they come, so I cans say I didn't have any challenge then because just a few who were coming ..." IDI, Facility in charge, site 1

Use of support groups appear to have resulted to the increased awareness of the conditions as one seemed to suggest: "R: Yes, I will say so because right now they have a support group, I won't mention the number but I know it is a support group that is almost exceeds a hundred plus patients who normally come together at least they are able to know this is a condition that it is not only me who has it, there other people actually living with it, they normally have a time to come and share experiences and challenges and what they are doing about it, which is a good step actually" IDI, Focal person, site 2

Finally, the training has enable facilities to plan on how to reach the cases and integrate them with the existing process and structures as manager reported " $R$ : Yes that is the major thing and people have taken it into their mind and now fully understand that NCDS is a silent disease that kills, so people have taken keen interest on it like right now we are talking of situation where we can have integrated outreaches, where NCDS can be part of the condition to be checked, now when you go for integrated services, there normally focused on ANC and then the cervical screening, HIV but now the way the trend is going have been incorporated we can have on the outreaches, when we have them here patient can be 
screened for free and it is just the same stripe, once you take the blood of sample for HIV you can use the same to check for sugars" IDI, manager, site 1

Perceptions on Innovative Learning Approaches for Building Capacity of Frontline Health Workers

It appears that there were many aspects of the mode of delivery for all the training approaches that were well received. Those trained through face to face, e-learning and m-learning overwhelmingly agreed with the statement that the training was worth their time (96\%) with all the groups having satisfaction rate of over $90 \%$. Very few $(17.5 \%)$ agreed that the they felt frustrated with the training process, the elearning group having the highest rate (27.8\%), compared to face to face group (13\%) and m-learning (17.2\%) and blended group at $14 \%$.

Accordingly, the respondents noted that the training achieved its objectives (92.1\%). Compared to other modes of training, $65 \%$ of those trained through e learning were satisfied with the approach used in delivering the training, compared to $90 \%$ in face to face, $89.1 \%$ of the Mlearning and blended group; $p<0.001$. In addition, majority of the participations agreed that the skills gained are being utilized ( $94.2 \%)$ with the blended group reporting the highest $96.1 \%$.

Qualitative evidence indicates various participants had varied views on the approaches to the training. Key informant interviewees were largely happy with the approach used in building the capacity of health workers to manage and diagnose diabetes and Asthma. Overall, there was agreement that the use of both the e-learning and M-learning were the modes of choice due to the ability to reach higher numbers, compared to traditional form of training which require huge amount of resource to reach a wider coverage. The two were further found to be convenient especially for busy health workers who might not have time to attend training workshops, associated with traditional forms of capacity building through training. Each of the approach used had merits and demerits as described below.

Face to face approach

Some preferred face to face with various reasons. "R: I still face to face for our type of people is the best and the mLearning , I find it very good especially for the CHVs it is fantastic but the eLearning program I think it has a problem and so some people are doing it well down there and again you know with eLearning sometimes someone can be doing it for the sake of finishing right?" IDI, NCD coordinator, site 2

The reasons for preference of face to face was greater attention and ability to ask questions when need arise, interaction with other participants and the advantage of the practicum such as how to use the spirometer, positioning of inhaler especially for children. Face to face was thus perceived to have a human feel and allows interaction with the facilitators which can enhance learning, nurturing different experiences and gaining from the interaction as some respondents noted

: "With the face to face you hear, listen, see and when it comes to practical's you feel so all those media something remain.And, you ask if you are not sure, also there is interaction and discussion and you gain 
different experiences from different people. Face to face is actually very effective according to me"IDI, NCD coordinator, site 3.

"...... You know face to face people get attention, you hear it first hand and you can ask if you are not sure and sometimes there is a practicum session like how to use the spirometer, if it is an inhaler how it is positioned, how can I support a child who needs an inhaler, I think seeing a picture and reading it on your own and someone sharing about it and asking you questions and they answer you and practically you see they are two different things". NCD coordinator site 2.

The demerits of face to face training was discussed in the context of costs of hosting the trainees as well as short time it takes for training which does not give enough time to digest everything;

" $R$ : That was their view, if I give my view from national training it is so compact but in a very short time it does not give you time to digest everything but again personally at my level, I know the training are very expensive at their level they may not understand, but just training forty people and accommodating them for five days it cost a lot of money and the resources are scarce so I want to believe that maybe the revision of curriculum it might be a bit easier to understand within that short period" IDI, NCD coordinator, site 3.

In addition, it may suffer from the competing tasks at places of work as a provider noted " $R$ : It is good but now getting all the people at once due to competing task, they are called for a training and then there is another training going on or taking place at the same time you find that not all people will be able to attend" IDI, Front line provider, site 1.

\section{E-Learning}

For eLearning, the probability of reaching many people was discussed as major merit. One of the respondent for instance noted; "I think with eLearning platform you can reach many people in a very short time, you can reach multiple health workers and you can communicate to them online if it is something they do not understand that is one advantage of eLearning program, you can reach so many people at a time", IDI, manager site 4.

It can also reach multiple health workers. Additionally it was perceived to sift the committed ones as indicated by the time taken to complete it: " $R$ : You see when it comes to eLearning you know who is committed because they will take up the module very fast, but those who are not committed some don't even bother or they take long and some have not even finished" IDI, NCD focal person, site 2. Which means that eLearning program requires commitment but can be limited by internet to complete the module.

Managers on the other hand reported that mleanring and eLearning has advantage to the lower level cadres. The reach was described in the light of availability of materials online that can be used by person who never attended the training thus updating them as well; "... I would prefer e-learning with mentorship attached. I'm saying e-learning because like Amref is doing some programs on management of 
pregnancy and whatever. You see we are already having notes on our computers. We are having computers in every department. So, everybody is opening, even a nurse who is on night duty can read things like updates on management of antenatal care and whatever... IDI, Health manager, site 2

The main disadvantages of eLearning and m-learning were related to limited access to internet or power. This may be pronounced because of the internet for the rural facilities where shortage of electricity or network coverage may limit access that may interfere with a smooth process of learning as indicated by the following excerpts;

"... There was that challenge many people were complaining about it, that is internet and not so many people have internet..." IDI, site 3.

"R: For me I will go with I mLearning because I believe all health care have access to phones and you can just do it at your own free time compared to what I got from eLearning (M coughs...) like there was an issue with internet connectivity at one point..." IDI, Front line provider, site 1

In other instances locations to conduct the self-learning makes the approach difficult for learner to effectively utilise the approach ; "...I don't mind, eLearning is good if we have time and maybe offices or somewhere to sit and do the eLearning", IDI, Site 4

Another interesting dimension that came out was the need to get support time to time during learning which makes eLearning model difficult to implement in cases people need help. This in view of this was seen to require some form of face of face interaction at one point or another as was mentioned by a facility in charge:

"... You know people cannot, sometimes people need to be led. So we can have somebody like a focal person on the same who can be going round and telling we are having this on the computer read, where you are having a challenge, do this. So in other words am saying, as much as we may advocate for elearning there must be some element of face to face..." IDI, Facility in charge, site 4

\section{M-learning}

The $\mathrm{mLearning}$ was perceived interesting and easy to especially because one can learn from anywhere and one can gauge oneself as the learning progress as was pointed that:

" $R$ : One, with the mobile I believe everyone has a mobile phone and you can do it, it is a mobile phone meaning that I have it wherever I go, so at any given time in a matatu at home or somewhere I am bored, I can actually go into it and read as opposed to eLearning that have to find a good place that is connected to internet and then start reading so that is the good thing with the mobile and in case of anything you can enquire from the others. Because there was that other group that was formed and in event there is an area you feel you are not sure of you can clarify to other members using that platform" IDI, Frontline provider 
The other merit was also discussed around mass reach to many people and with the current trend of use of technology provides an opportunity for people to learn at their own time;

"It's very convenient for, particularly for us who are busy, you can easily log in and go through. So it's the method that is advisable I think. That's the direction we are moving particularly if you want to train a mass of health workers. You don't want to affect services going on...."IDI, Manager, site 4.

The demerits lie in the requirement of an internet enabled phones which sometimes is assumed to be available yet may not be universal. It was also challenged by utility of the phones where some could not easily navigate it or when they share a phone with others it may limit learning.

"R: One that I have seen is that there was some certain types of phones that the responses were taking too long to download, I don't know whether it is an issue with the network or it was an issue with phones, but I don't know, I am not sure of. And then another thing with the phone with such a thing that is too detailed, you find it coming in bits by the time you get to understand the whole concept you actually forgotten what you have read previously, so if it can be shortened to make it short and clear" IDI, frontline provider, site 3

"I would prefer e-learning with mentorship attached. I'm saying e-learning because like Amref is doing some programs on management of pregnancy and whatever. You see we are already having notes on our computers. We are having computers in every department. So everybody is opening, even a nurse who is on night duty is able to read what ehh...like updates on like management of antenatal care and whatever. So if we had those kinds of notes on our computers and then we must have somebody. You know people cannot, sometimes people need to be led. So we can have somebody like a focal person on the same who can be going round and telling we are having this on the computer read, where you are having a challenge, do this. So in other words am saying, as much as we may advocate for e-learning there must be some element of face to face. IDI, Mid-level manager, site 2

Additionally, there may be limitations in terms of language used in the content as some may require using a language that can be understood more widely in cases of individuals who may not understand English for example

"... I would advise that for m-learning to provide content even in Kiswahili because most of us we had challenges because the content was given in English" IDI, CHV, site 1

This means that there may be cost associated with developing content in more than one language, which may initially be costly for the approach. Nevertheless, it was noted that even after going through the course, there was a common thread that there may be need for refresher training to remind learners of what they have learnt regardless of the approach used

"...And there was no review... and you know... with human beings, you can forget ...that's is why you see people go for refresher courses. I thought after finishing the course" IDI, front line manager, site 3 
In a nutshell, table 7 summarises the merits and demerits of the various training approaches as shown:

\section{Table 7: Merits and demerits of the different training approaches}

\section{Discussion}

The operational research aimed at assessing the effectiveness of utilising different innovative learning approaches in building capacity of frontline health workers on the management and control of diabetes and asthma in relation to Identification, diagnosis, management, referral-linkage with facilities, promoting Behaviour change, maintaining records, follow-up and service delivery. It also explored the perceptions of frontline health workers and community level actors (CHVs and CHEWS) on the innovative learning approaches used in building the capacity of frontline health workers in the management and control of diabetes and asthma.

Effectiveness of capacity building approaches used

From the results, the use of technology shown in e and mlearning supports the evidence that the use of information technology in the educational context could enable a flexible, efficient and scalable training as well as delivery of latest evidence, innovation as part of both preservice and continuous, in-service education. This clearly came out from the participants in this study. The potential positive impact of e \& mLearning on health workforce capacity development was been widely acknowledged and endorsed. From the results similarly, there is need however to combine eLearning with the traditional education approaches like face-to-face learning to offer some blended learning for those competencies that need face to face experiences.

In terms of participant's reaction to the training, the study examined participant's level of satisfaction, engagement and whether the training was relevant. This study has demonstrated that trainings were well received, beneficial and met the expectations of the participants. In terms of whether the training was of any value, there was high appreciation across each model with rates of above $95 \%$ and supported by qualitative data that showed that the trainings played a key role in preparing them to address asthma and diabetes in their area of jurisdiction. Nearly all participants felt that the training achieved its purpose and that they were satisfied with the approach used in delivering the training with differences between the group. Satisfaction was lower among the eLearning approach at $64 \%$ compared with the rest that was between 89 and $90 \%$. The lower rating for e-learning could be attributed to shortcomings such as access to reliable internet to support a seamless learning encounter and the demand for online forum for support to learners. Despite this, all the training models were found to be engaging in the sense that participants were actively involved, contributed to the learning experience and had the opportunity to use or apply what learnt on their job.

There is however room for improvement, to address some of the shortcomings raised under each method of delivery. For instance, the association of face to face training with promoting a human aspect, might point to the need to make IT based training approaches more interactive and supportive by features such 
as chat rooms and use of online support desks. Such innovations are likely to make feel supported and provide opportunities to interact with one another.

The different training models were equally successful in equipping learners with the intended skills for the diagnosis and management of diabetes and asthma. All the core aspects of learning, that include acquisition of the intended knowledge, skills, attitude, confidence and commitment based on their participation in the training showed impressive scores across the different models used for delivering training content. This study has demonstrated that participants were equipped with knowledge, skills and the confidence to diagnose and manage diabetes and asthma. Majority of the participants were able to correctly identify types of diabetes with no differences between the groups trained by various methods. In addition, most of the trainees regardless of training model were able to mention at least three main symptoms of diabetes: frequent urination, hunger and thirst in over $90 \%$ of cases with no differences between group. Knowledge levels were also higher in those who mentioned complications of diabetes such as heart, kidney and foot problems in diabetic patients in between $77-90 \%$ of the responses. Weight control, healthy diet and regular exercise were mentioned as the main preventive methods of diabetes in over $90 \%$ of the response.

Based on these findings it is evident that, participants acquired knowledge and skills across the entire spectrum of care and management of diabetes. Similar observations were made for the case of Asthma including a good understanding of the myths around the diseases including its social effects which exhibited variations by type of training model for example, $86 \%$ of those attending Mlearning model reported that Asthma can affect student's studies compared with the rest that reported over $90 \%$.

Despite the high level of knowledge and skills, there were notable differences in terms of the participants' confidence in several aspects of disease management including diagnosis, treatment and referral, which perhaps indicate the ability of health workers to commit themselves to manage the NCD. For example, the percentage of those who reported that Postpartum care visit would be used for diabetes education intervention varied from $48 \%$ among face to face group to $87 \%$ among the eLearning group. This was the case for those who mentioned Antenatal care visit with percentage ranging from $66 \%$ to $87 \%$ between the groups. Although it is difficult to assess the rationale behind these differences there is a possibility that the roles of different frontline health workers might affect their perception of opportunities for intervention. Overall, frontline health workers were more confident after the training, in terms of preparedness and readiness to diagnose and manage both diabetic and asthmatic cases.

In terms of changes in behavior following the training, several processes and systems that reinforce and encourage positive action to address both diabetes and asthma were noted. These included the facility preparedness to support the trainee to apply the knowledge gained by putting in place structures and systems that support service delivery in relation to the two NCDs. Key among the positive behaviors reported include the availability of adequate drugs to treat both diabetes and asthma, education and awareness creation at the community level and existence of a strong leadership to spearhead facility preparedness to respond to the two NCDs. Despite the presence of strong leadership to advocate for 
resources to address diabetes and asthma, it was apparent that most health facilities still lacked adequate equipment to support diabetes and asthma diagnosis. It is quite telling, in the sense that fewer people indicated they always get what they want for managing diabetes and childhood asthma and this aspect was reported in very low rates of less than $36 \%$ indicating the drivers at the work place are likely to make it hard for them to practice the aspect leant through training.

In terms of improvements in organizational performance, i.e the degree to which targeted outcomes occur because of the training and the support and accountability package, this study assessed two measures. First the results/outcome of the training on the facilities where the trainees are working and second, the short-term observations and measurements among the trainees, that might suggest that critical behaviors are on track to create a positive impact on desired results. Overall, an overwhelming majority irrespective of the model of training felt the skills gained were being utilized in the diagnosis and management of both diabetes and asthma. For instance, the facilities in which they were working had initiated several efforts to address the two NCDs. In one site for instance, community screening for diabetes during the monthly action days was one of the key developments following the training. Others include the establishment of 28 model asthma clinics, which was attributed to the knowledge gained from the training. In addition, the trainees noted that their approach to diagnosis and management had changed and they felt confident when managing their patients. At the organisational level, the trainings influenced the establishment and development of strategic plans, structures and strategies to champion the diagnosis and management of the two NCDs, which represent a critical step in ensuring the sustainability of the training. These positive developments in organisational performance were however reported by those trained through face to face and e-learning. For instance, those trained through $\mathrm{m}$ learning were less likely to report that they were supported to put their skills into practice.

For future programming similar approaches should consider the following options to improve implementation and content delivery: Firstly, consider content development and deployment for both elearning and mlearning. This means the content need to be easily retrievable when one is revising especially for lower level cadres and provide ability to have scheduled interactive session that may cover new knowledge and allow interactions. It's important to utilise local mentors to allow for follow up and cementing skills gained from the online platform and plan for scheduled practicum if need be that is tied to continuous professional development. Secondly, it is crucial to set up conducive environment for learning by ensuring context support use of technology by conducting a feasibility assessment to assess; adaptation needed for local network provision for effective learning. Continuity of support when of line and manage expectations of users when system has a down moment. Thirdly, Data quality and documentation must be considered through development of a robust system of data management and linkages between community-facility and back (ensuring referral forms and communication is place) and support in the development of clinical forms at facility level that can provide update data for management of both conditions that can be traced when data is needed for action

Conclusions

Page 23/34 
The different models of training used in building the capacity of frontline health workers to diagnose and manage diabetes and asthma were very effective. The trainees were satisfied with the way the training content was delivered, the level of engagement during the training and that the models used was relevant to the different cadre. In addition, the training was successful in increasing their knowledge skills, the confidence and commitment of frontline health workers to spearhead the preventive and curative aspects relating to diabetes and asthma. A lot of progress has been made at the health facility and community level in terms of paving way for the development of structures and systems to spearhead the diagnosis and management of both diabetes and asthma. Key indicators of this progress include awareness creation and community education on NCDs, community screening for NCDs and ensuring that health facilities are well stocked with appropriate drugs and diagnostics. At the individual level, trained frontline health workers now feel prepared and well equipped to provide services to their clients, and are more committed to spearhead diagnosis and management of diabetes and asthma at their areas of jurisdiction. Health care managers are also actively mobilising resources to tackle diabetes and asthma, by developing diabetes and asthma specific annual work plans and ensuring that they are incorporate in the county health sector strategic plans. Taken together, these developments indicate changes in behaviour in terms of the application of knowledge and skills from the training.

No training model was superior in terms of the degree of satisfaction, improving knowledge of frontline health workers towards the management of childhood asthma and diabetes or shaping behaviour change and organisational performance. Instead, each of the model had intrinsic advantages and disadvantages. For instance, face to face training was found to be more engaging and supportive of adult learning owing to the human interaction and opportunity for peer support. However, it was rather disruptive and costly, and therefore limiting in terms of reach and access. On the contrary, both e-learning and m-learning can reach more health workers in a convenient manner, since they do not have to leave their workstations. The effectiveness of both e-learning and m-learning are heavily dependent on access to internet, which has the potential to limit its access especially among the CHVs.

Despite the success in building the capacity of frontline health workers, it appears that the health system context is likely to erode the ability to practice the knowledge and skills gained making it hard for the trainees to use the skills in the long term. Logistical challenges of access to internet and other necessary infrastructure and support services is likely to hamper the success of the ICT-based learning approaches. In as much as technology-based learning is key to reaching many people at the same time, human interaction and practical elements are crucial in enhancing learning with the health care setting.

Frontline health workers welcome the use of innovative approaches to capacity building. The use of both e-learning and m-learning for instance are very suited for busy health workers who are often faced with time constraints when it comes to attending traditional class-based training. Acceptability of training models by the target beneficiaries is an important element towards the success of any capacity building initiative. Besides the cost, the acceptability of ICT based capacity building derive from the fact that they are less disruptive, since heath workers can be trained at their convenience, and their promise to build a critical mass of health workers with required knowledge and skills to address health challenges.

Page 24/34 


\section{Declarations}

Conflict of Interest

None declared

Authors' contributions

1. Sarah Kosgei

Roles Project administration, Conceptualization, Methodology, Supervision, Writing - review \& editing Affiliation Amref Health Africa, Kenya

2. Colleta Kiilu

Roles Project administration, Conceptualization, Methodology, Supervision, writing, review \& editing Affiliation Amref Health Africa, Kenya

3. Bryson Sifuma

Roles, Methodology, Supervision, review \& editing

Affiliation Amref Health Africa, Kenya

4. Christopher Were

Roles Project administration, funding, review \& editing

GSK, Kenya

5. Anastasiah Kimeu

Roles Conceptualization, Methodology, reviewing \& validation

Affiliations Affiliation Amref Health Africa, Kenya

6. George Kimathi

Roles Conceptualization, Funding acquisition, Methodology, Supervision, \& validation

Affiliations Affiliation Amref Health Africa, Kenya

7. Sarah Jefferys

Roles Conceptualization, Methodology, reviewing \& validation 
Affiliations Affiliation Amref Health Africa, UK

\section{Alice Aiello}

Roles Conceptualization, Methodology, reviewing \& validation

Affiliations Affiliation Amref Health Africa, UK

\section{Ethics approval and consent to participate}

Ethical approval for this study was given be the Amref health Africa Ethics and Scientific Review Committee (ESRC). REF - AMREF_ESRC P485/2018

\section{References}

1. Alwan A, MacLean DR, Riley LM, d'Espaignet ET, Mathers CD, Stevens GA, et al. Monitoring and surveillance of chronic non-communicable diseases: progress and capacity in high-burden countries. Lancet [Internet]. 2010 Nov 27 [cited 2019 Jan 27];376(9755):1861-8. Available from: http://www.ncbi.nlm.nih.gov/pubmed/21074258

2. Alwan A, Armstrong T, Bettcher D, Branca F, Chisholm D, Ezzati M, et al. Global status report on noncommunicable diseases [Internet]. 2010 [cited 2019 Jan 27]. Available from:

http://www.who.int/about/licensing/copyright_form/en/index.html

3. WHO. Noncommunicable diseases key facts [Internet]. WHO fact sheet. 2018 [cited 2019 Jan 27]. Available from: https://www.who.int/news-room/fact-sheets/detail/noncommunicable-diseases

4. WHO. Chapter 1-Burden: mortality, morbidity and risk factors Chapter 1 [Internet]. [cited 2019 Jan 27]. Available from: https://www.who.int/nmh/publications/ncd_report_chapter1.pdf

5. WHO. Non-communicable disease country profiles, Kenya. Geneva: WHO. 2011;

6. Ministry of Health Kenya. Kenya Strategy for the prevention and control of non-communicable doseases. (2015-2020). 2015.

7. El-Busaidy H, Dawood M, Kasay A, Mwamlole C, Koraya N, Parpia H. How Serious is the Impact of Type II Diabetes in Rural Kenya? [Internet]. Vol. 7, The Open Diabetes Journal. 2014 [cited 2019 Jan 27]. Available from: https://pdfs.semanticscholar.org/8adb/81f65d05618e860448bab5dc9ba13813a1d6.pdf

8. IDA. International Diabetes Federation. IDF Diabetes Atl Ass Sixth edition. IDF Diabetes. 2014;

9. Adeloye D, Chan KY, Rudan I, Campbell H. An estimate of asthma prevalence in Africa: a systematic analysis. Croat Med J [Internet]. 2013;54(6):519-31. Available from:

http://www.pubmedcentral.nih.gov/articlerender.fcgi?

artid $=3893990 \&$ tool $=$ pmcentrez\&rendertype $=$ abstract 
10. Spathis A, Booth S. End of life care in chronic obstructive pulmonary disease: in search of a good death. Int J Chron Obstruct Pulmon Dis [Internet]. 2008 [cited 2019 Jan 27];3(1):11-29. Available from: http://www.ncbi.nlm.nih.gov/pubmed/18488426

11. W M. Control of non-communicable disease in Kenya, past present and future. Nairobi: Ministry of Health. 2009;

12. Ministry of of Health. Kenya National Strategy for the Prevention and Control of Non-Communicable Diseases. 2015;

13. Ministry of public health and sanitation. Guidelines for Asthma Management in Kenya [Internet]. Nairobi; 2011. Available from: http://apps.who.int/medicinedocs/documents/s21973en/s21973en.pdf

14. Amref Health Africa. Quarterly Report: Management and control of NCDs (Diabetes and Childhood Asthma) in Kenya. Nairobi: Amref. 2017.

15. Ministry of Health. Health Sector Human Resources Strategy 2014-2018. Strateg Manag Handb. 2014;1-22.

16. Frøen JF, Myhre SL, Frost MJ, Chou D, Mehl G, Say L, et al. eRegistries: Electronic registries for maternal and child health. BMC Pregnancy Childbirth [Internet]. 2016;16(1):11. Available from: https://doi.org/10.1186/s12884-016-0801-7

17. D K. Kirkpatrick's Four Levels of Training Evaluation in Detail [Internet]. 1959 [cited 2019 Jan 27]. Available from: www.businessballs.com

\section{Tables}

Table 1: Levels of assessment using the Kirkpatrick model 


\begin{tabular}{|c|c|}
\hline Level & Focus of the assessment \\
\hline $\begin{array}{l}\text { Reaction- The degree to which participants find the } \\
\text { training favourable, engaging and relevant to their } \\
\text { jobs }\end{array}$ & $\begin{array}{l}\text { Satisfaction-Trainee's account /views on the } \\
\text { importance/value of the training, its success, } \\
\text { strengths, weaknesses, mode of delivery and whether } \\
\text { it met their expectations } \\
\text { Engagement-are participants actively involved in and } \\
\text { contributing to the learning experience } \\
\text { Relevance- do training participants have the opportunity } \\
\text { to use or apply what } \\
\text { Learned in training on the job? Which areas and how } \\
\text { are they applying it? }\end{array}$ \\
\hline $\begin{array}{l}\text { Learning- The degree to which participants acquire } \\
\text { the intended knowledge, skills, attitude, confidence } \\
\text { and commitment based on their participation in the } \\
\text { training }\end{array}$ & $\begin{array}{l}\text { Knowledge attitude \& skills-Trainee's } \\
\text { increase/achievements in terms of knowledge, skills } \\
\text { and attitudes in relation to the management of } \\
\text { diabetes and asthma } \\
\text { Confidence- are participants feel comfortable to } \\
\text { diagnose, manage or referral clients? } \\
\text { Commitment - to what extent are they willing to attend } \\
\text { to the cases and follow up clients }\end{array}$ \\
\hline $\begin{array}{l}\text { Behavior- The degree to which participants apply } \\
\text { what they learned during training when they are } \\
\text { back on the job }\end{array}$ & $\begin{array}{l}\text { Focuses on the degree to which the } \\
\text { knowledge/skills/attitude/confidence/commitment } \\
\text { learnt during training is applied to the trainee's job } \\
\text { Required Drivers- Processes and systems that } \\
\text { reinforce, encourage and reward performance of } \\
\text { critical behaviors on the job }\end{array}$ \\
\hline $\begin{array}{l}\text { Results/Organizational performance- The degree to } \\
\text { which targeted outcomes occur because of the } \\
\text { training and the support and accountability package }\end{array}$ & $\begin{array}{l}\text { Measure the results/outcome of the training in the } \\
\text { long-term, to the health facilities where the trainees } \\
\text { are working } \\
\text { Leading Indicators- Short-term observations and } \\
\text { measurements suggesting that critical behaviors are } \\
\text { on track to create a positive impact on desired results }\end{array}$ \\
\hline
\end{tabular}

Table 2: Number of interviews conducted by type of training model and sites 


\begin{tabular}{|l|l|l|l|l|}
\hline Mode of Training & Face to face & m-Learning & e-Learning & Blended \\
\hline Category of health worker & $\begin{array}{l}\text { Frontline health } \\
\text { workers }\end{array}$ & $\begin{array}{l}\text { CHEWs \& Community } \\
\text { Health Volunteers }\end{array}$ & $\begin{array}{l}\text { Frontline health } \\
\text { workers }\end{array}$ & \\
\hline Total trained & 238 & 1100 & 864 & 126 \\
\hline $\begin{array}{l}\text { Proposed sample size (a third } \\
\text { for each category) }\end{array}$ & 79 & 366 & 288 & 128 \\
\hline $\begin{array}{l}\text { Total sample based on } \\
\text { availability and saturation }\end{array}$ & 100 & 64 & 90 & \\
\hline Total sample & 382 & \multicolumn{5}{|l|}{} \\
\hline Qualitative interviews & Category of Healthcare workers & $\begin{array}{l}\text { Facility In } \\
\text { charge }\end{array}$ & CHV \\
\hline County & NCD \\
& coordinator & $\begin{array}{l}\text { Frontline health } \\
\text { workers }\end{array}$ & 2 & 5 \\
\hline Nyeri & 1 & 2 & 2 & 7 \\
\hline Nairobi & 2 & 2 & 2 & 5 \\
\hline Kakamega & 1 & 3 & 3 & 5 \\
\hline Kilifi & 1 & 9 & 9 & 22 \\
\hline Total & 5 & 2 & 2 \\
\hline
\end{tabular}

Table 3: Characteristics of clients interviewed 


\begin{tabular}{|c|c|c|c|c|c|}
\hline Gender & Face to Face $n=100$ (\%) & $\begin{array}{l}\text { e-learning } \\
\mathrm{n}=90(\%)\end{array}$ & $\begin{array}{l}\text { mlearning } \\
\mathrm{n}=64(\%)\end{array}$ & $\begin{array}{c}\text { Blended } \\
\mathrm{n}=128(\%)\end{array}$ & $\begin{array}{c}\text { Total } \\
\mathrm{n}=382(\%)\end{array}$ \\
\hline Female & $71(71.0)$ & $63(70.0)$ & $57(89.1)$ & $96(75.0)$ & $287(75.1)$ \\
\hline Male & $29(29.0)$ & $27(30.0)$ & $7(10.9)$ & $32(25.0)$ & $95(24.9)$ \\
\hline \multicolumn{6}{|l|}{ Median Age } \\
\hline Median (SD) & $42.5(11.5)$ & $35.7(8.7)$ & $43.9(9.6)$ & $39.5(9.5)$ & $40.1(10.3)$ \\
\hline \multicolumn{6}{|c|}{ Respondents based in the following departments } \\
\hline $\mathrm{MCH}$ unit & $5(5.0)$ & $7(12.2)$ & $2(3.1)$ & $5(3.9)$ & $19(5.0)$ \\
\hline Maternity unit & $4(4.0)$ & $11(10.0)$ & $0(0.0)$ & $3(2.3)$ & $18(4.7)$ \\
\hline Specialised clinics & $7(7.0)$ & $9(48.9)$ & $0(0.0)$ & $1(0.8)$ & $17(4.5)$ \\
\hline General outpatient & $22(22.0)$ & $44(3.3)$ & $1(1.6)$ & $2(1.6)$ & $\begin{array}{l}69 \\
(18.1) \\
\end{array}$ \\
\hline Community & $45(45.0)$ & $3(11.1)$ & $59(92.2)$ & $89(69.5)$ & 196(51.3) \\
\hline Laboratory & $6(6.0)$ & $10(4.4)$ & $0(0.0)$ & $3(2.3)$ & $19(5.0)$ \\
\hline Pharmacy & $3(3.0)$ & $4(2.2)$ & $0(0.0)$ & $2(1.6)$ & $9(2.4)$ \\
\hline Others & $8(8.0)$ & $2(2.2)$ & $2(3.1)$ & $3(2.3)$ & $15(3.9)$ \\
\hline \multicolumn{6}{|l|}{ Professional qualifications } \\
\hline Clinical officer & $11(11.0)$ & $21(23.3)$ & $0(0.0)$ & $12(9.4)$ & $44(11.5)$ \\
\hline Nurse (all cadres) & $15(15.0)$ & $31(34.4)$ & $3(4.7)$ & $11(8.6)$ & $60(15.7)$ \\
\hline Community health volunteer & $40(40.0)$ & $0(0.0)$ & $34(53.1)$ & $52(40.6)$ & $126(33.0)$ \\
\hline Laboratory technologist & $9(9.0)$ & $12(13.3)$ & $0(0.0)$ & $4(3.1)$ & $25(6.5)$ \\
\hline Nutritionist & $5(5.0)$ & $11(12.2)$ & $0(0.0)$ & $2(1.6)$ & $18(4.7)$ \\
\hline Pharmaceutical Technologists & $5(5.0)$ & $8(8.9)$ & $0(0.0)$ & $3(2.3)$ & $16(4.2)$ \\
\hline CHEWs & $11(11.0)$ & $3(3.3)$ & $5(7.8)$ & $13(10.2)$ & $32(8.4)$ \\
\hline Other & $4(4.0)$ & $4(4.4)$ & $22(34.4)$ & $31(24.2)$ & $61(16.0)$ \\
\hline \multicolumn{6}{|l|}{ Period having worked in years } \\
\hline Entire professional life & $10.8(8.2)$ & $10.3(8.4)$ & $9.0(5.3)$ & $8.2(6.6)$ & $9.5(7.3)$ \\
\hline Current facility & $5.8(4.7)$ & $4.4(4.1)$ & $6.5(4.0)$ & $5.4(3.1)$ & $5.5(4.0)$ \\
\hline Current unit / department & $5.4(4.3)$ & $3.6(2.9)$ & $6.4(4.0)$ & $4.0(5.3)$ & $3.1(3.7)$ \\
\hline
\end{tabular}

Table 4: Knowledge levels on Diabetes 


\begin{tabular}{|c|c|c|c|c|c|}
\hline $\begin{array}{l}\% \text { of respondents who mentioned the } \\
\text { following as symptoms of diabetes }\end{array}$ & $\begin{array}{l}\text { Face to Face } \\
n=100\end{array}$ & $\begin{array}{c}\mathrm{e}- \\
\text { learning } \\
\mathrm{n}=90\end{array}$ & $\begin{array}{c}\text { Mlearning } \\
\mathrm{n}=64\end{array}$ & $\begin{array}{c}\text { Blended } \\
\mathrm{n}=128\end{array}$ & $\begin{array}{c}\text { Total } \\
\mathrm{n}=382\end{array}$ \\
\hline Frequent urination & $94(94.0)$ & $88(81.1)$ & $63(98.4)$ & $127(99.2)$ & $372(97.4)$ \\
\hline Frequent hunger & $91(91.0)$ & $73(98.9)$ & $59(92.2)$ & $114(89.1)$ & $337(88.2)$ \\
\hline Frequent thirst & $97(97.0)$ & $89(100)$ & $61(95.3)$ & $126(98.4)$ & $373(97.6)$ \\
\hline \multicolumn{6}{|c|}{$\%$ of respondents who mentioned the following as complications of diabetes } \\
\hline Heart disease & $74(74.0)$ & $65(91.1)$ & $51(79.7)$ & $104(81.3)$ & $294(77.0)$ \\
\hline Kidney disease & $88(88.0)$ & $82(96.7)$ & $55(85.9)$ & $108(84.4)$ & $333(87.2)$ \\
\hline Eye disease & 93(93.0) & $87(97.8)$ & $55(85.9)$ & $116(90.6)$ & $351(91.9)$ \\
\hline Foot problems & $97(97.0)$ & $88(0.0)$ & $60(93.8)$ & $122(95.3)$ & $367(96.1)$ \\
\hline \multicolumn{6}{|c|}{$\%$ of respondents who mentioned the following as ways of preventing diabetes } \\
\hline Health diet & $100(100)$ & $88(97.8)$ & $64(100)$ & $128(100)$ & $382(99.5)$ \\
\hline Regular exercise & $98(98.0)$ & $90(93.3)$ & $64(100)$ & $127(99.2)$ & $379(99.2)$ \\
\hline Weight control & $95(95.0)$ & $84(100)$ & $63(98.4)$ & $120(93.8)$ & $362(94.8)$ \\
\hline Don't know & $0(0.0)$ & $1(1.1)$ & $2(3.1)$ & $6(4.7)$ & $9(2.4)$ \\
\hline \multicolumn{6}{|c|}{$\%$ of respondents who reported that the following areas can be used for diabetes education intervention: } \\
\hline Postpartum care visit & $48(48.0)$ & $67(86.7)$ & $36(56.3)$ & $73(57.0)$ & $224(58.6)$ \\
\hline Antenatal care visit & $70(70.0)$ & $78(86.7)$ & $49(76.6)$ & $84(65.6)$ & $281(73.6)$ \\
\hline Child welfare clinic & $70(70.0)$ & $78(72.2)$ & $49(76.6)$ & $84(65.6)$ & $281(73.6)$ \\
\hline Family planning & $63(63.0)$ & $65(96.7)$ & $44(68.8)$ & $86(67.2)$ & $258(67.5)$ \\
\hline Outpatient clinic & $76(76.0)$ & $87(67.8)$ & $58(90.6)$ & $98(76.6)$ & $319(83.5)$ \\
\hline TB screening and detection in pregnancy & $58(58.0)$ & $61(67.8)$ & $38(59.4)$ & $65(50.8)$ & $222(58.1)$ \\
\hline \multicolumn{6}{|c|}{$\%$ of respondents who reported the following as symptoms of hypoglycemia } \\
\hline Sweating & $87(87.0)$ & $77(84.4)$ & $51(79.7)$ & $97(75.8)$ & $312(81.7)$ \\
\hline Dizziness & $89(89.0)$ & $76(84.4)$ & $54(84.4)$ & $117(91.4)$ & $336(88.0)$ \\
\hline Weakness/fatigue & $94(94.0)$ & $84(93.3)$ & $57(89.1)$ & $115(89.8)$ & $350(91.6)$ \\
\hline \multicolumn{6}{|c|}{$\%$ of respondents who reported the following as true } \\
\hline $\begin{array}{l}\text { Diabetes is a condition in which the blood } \\
\text { sugar is high }\end{array}$ & $75(75.0)$ & $70(77.8)$ & $60(93.8)$ & $112(87.5)$ & $317(83.0)$ \\
\hline $\begin{array}{l}\text { Diabetes type } 2 \text { is a condition of body not } \\
\text { responding to insulin }\end{array}$ & $77(77.0)$ & $74(82.2)$ & $52(81.3)$ & $104(81.3)$ & $307(80.4)$ \\
\hline Diabetes is non-contagious & $86(86.0)$ & $85(94.4)$ & $59(92.2)$ & $120(93.8)$ & $350(91.6)$ \\
\hline Diabetes is not curable & $72(72.0)$ & $67(74.4)$ & $55(85.9)$ & $107(83.6)$ & $301(78.8)$ \\
\hline
\end{tabular}

Table 5: Knowledge levels on Asthma 


\begin{tabular}{|c|c|c|c|c|c|}
\hline $\begin{array}{l}\% \text { of respondents who reported the following } \\
\text { as true of Asthma }\end{array}$ & $\begin{array}{l}\text { Face to } \\
\text { Face } \\
\mathrm{N}=100\end{array}$ & $\begin{array}{l}\text { Elearning } \\
\mathrm{N}=90\end{array}$ & $\begin{array}{l}\text { Mlearning } \\
\mathrm{N}=64\end{array}$ & $\begin{array}{c}\text { Blended } \\
\mathrm{N}=128\end{array}$ & $\begin{array}{c}\text { Total } \\
\mathrm{N}=382\end{array}$ \\
\hline $\begin{array}{l}\text { Asthma is a communicable disease spread from } \\
\text { one person to another }\end{array}$ & $9(9.0)$ & $6(6.7)$ & $7(10.9)$ & $17(13.3)$ & $39(10.2)$ \\
\hline $\begin{array}{l}\text { Symptoms of asthma are difficulty in breathing, } \\
\text { cough and chest congestion }\end{array}$ & $95(95.0)$ & $86(95.6)$ & $63(98.4)$ & 126(98.4) & $370(96.9)$ \\
\hline Asthma is a hereditary disease & $79(79.0)$ & $80(88.9)$ & $51(79.7)$ & $104(81.3)$ & $314(82.2)$ \\
\hline $\begin{array}{l}\text { Sometimes asthma can be caused by an } \\
\text { infection due to microorganism }\end{array}$ & $56(56.0)$ & $57(63.3)$ & $39(60.9)$ & $87(68.0)$ & $239(62.6)$ \\
\hline $\begin{array}{l}\text { Asthma is a chronic disease which needs } \\
\text { treatment for long time }\end{array}$ & $88(88.0)$ & $86(95.6)$ & $59(92.2)$ & $114(89.1)$ & $347(90.8)$ \\
\hline Asthma predominantly effect female children & $10(10.0)$ & $18(20.0)$ & $11(17.2)$ & $11(8.6)$ & $50(13.1)$ \\
\hline $\begin{array}{l}\text { In children physical activity and exercise can } \\
\text { induce asthma attack }\end{array}$ & $62(62.0)$ & $62(68.9)$ & $33(51.6)$ & $69(53.9)$ & $226(59.2)$ \\
\hline Asthma occurs in specific age among children & $19(19.0)$ & $25(27.8)$ & $13(20.3)$ & $27(21.1)$ & $84(22.0)$ \\
\hline $\begin{array}{l}\text { Asthmatic attacks are more usually occur in } \\
\text { day time as compare to night }\end{array}$ & 13(13.0) & $9(10.0)$ & $13(20.3)$ & $14(10.9)$ & $49(12.8)$ \\
\hline Asthma attack can cause death & $92(92.0)$ & $89(98.9)$ & $63(98.4)$ & $\begin{array}{r}122 \\
(95.3) \\
\end{array}$ & $366(95.8)$ \\
\hline $\begin{array}{l}\text { Asthma be completely controlled by using } \\
\text { medication regularly for longer period of time }\end{array}$ & $94(94.0)$ & $85(94.4)$ & $64(100)$ & $122(95.3)$ & $365(95.5)$ \\
\hline Asthma can be completely cured & $33(33.0)$ & $31(34.4)$ & $27(42.2)$ & $47(36.7)$ & $138(36.1)$ \\
\hline Passive Smoking can worsen asthma & 95(95.0) & $90(100.0)$ & $61(95.3)$ & 124(96.9) & $370(96.9)$ \\
\hline Inhalers are used to treat asthmatic attack & $90(90.0)$ & $82(91.1)$ & $56(87.5)$ & 116(90.6) & $344(90.1)$ \\
\hline Asthma is caused by a swelling of the lung & $44(44.0)$ & $34(37.8)$ & $36(56.3)$ & $79(61.7)$ & 193(50.5) \\
\hline $\begin{array}{l}\text { In asthmatic children avoiding milk may } \\
\text { improve their condition }\end{array}$ & $31(31.0)$ & $34(37.8)$ & $14(21.9)$ & $29(22.7)$ & $108(28.3)$ \\
\hline Asthma can affect student's studies & $95(95.0)$ & $89(98.9)$ & $55(85.9)$ & $120(93.8)$ & $359(94.0)$ \\
\hline Asthma is caused by mucus production & $39(39.0)$ & $33(36.7)$ & $14(21.9)$ & $63(49.2)$ & $149(39.0)$ \\
\hline Asthma is caused by muscle tightening & $60(60.0)$ & $54(60.0)$ & $30(46.9)$ & $84(65.6)$ & $228(59.7)$ \\
\hline URI can trigger acute asthma attack & $81(81.0)$ & $75(83.3)$ & $34(53.1)$ & $39(30.5)$ & 229 59.9) \\
\hline Weather can trigger acute asthma attack & 95(95.0) & 89(98.9) & $63(98.4)$ & $127(99.2)$ & 374 97.9) \\
\hline Exercise can trigger acute asthma attack & $74(74.0)$ & $78(86.7)$ & $34(53.1)$ & $81(63.3)$ & $267(69.9)$ \\
\hline Smoking can trigger acute asthma attack & $94(94.0)$ & $88(97.8)$ & $58(90.6)$ & $125(97.7)$ & $365(95.5)$ \\
\hline $\begin{array}{l}\text { Allergens: such as pets, mice, cockroaches, } \\
\text { dust, mold, cleaning supplies (laundry } \\
\text { detergent, kitchen/bathroom sprays) can } \\
\text { trigger acute asthma }\end{array}$ & $96(96.0)$ & $89(98.9)$ & $62(96.9)$ & $128(100)$ & $375(98.2)$ \\
\hline
\end{tabular}

Table 6: Perception of post training experience 


\begin{tabular}{|l|c|c|c|c|c|}
\hline $\begin{array}{l}\text { \% of respondents agreeing with the following } \\
\text { regarding post training experiences }\end{array}$ & $\begin{array}{c}\text { Face to } \\
\text { Face } \\
\mathrm{n}=100(\%)\end{array}$ & $\begin{array}{c}\text { e-learning } \\
\mathrm{n}=90(\%)\end{array}$ & $\begin{array}{c}\mathrm{m}- \\
\text { learning } \\
\mathrm{n}=64(\%)\end{array}$ & $\begin{array}{c}\text { Blended } \\
\mathrm{n}=128(\%)\end{array}$ & $\begin{array}{c}\text { Total } \\
\mathrm{n}=382(\%)\end{array}$ \\
\hline $\begin{array}{l}\text { I am well equipped with skills to address } \\
\text { childhood asthma. }\end{array}$ & $79(79.0)$ & $76(84.4)$ & $61(95.3)$ & $111(86.7)$ & $327(85.6)$ \\
\hline $\begin{array}{l}\text { I am well equipped with skills to address } \\
\text { diabetes }\end{array}$ & $95(95.0)$ & $86(95.6)$ & $61(95.3)$ & $118(92.2)$ & $360(94.2)$ \\
\hline I feel good about this supervision system. & $96(96.0)$ & $88(97.8)$ & $61(95.3)$ & $122(95.3)$ & $367(96.1)$ \\
\hline $\begin{array}{l}\text { I can teach my colleagues the skills I learnt } \\
\text { from the training }\end{array}$ & $97(97.0)$ & $82(91.1)$ & $63(98.4)$ & $124(96.9)$ & $366(95.8)$ \\
\hline $\begin{array}{l}\text { My approach to diagnosis and management of } \\
\text { diabetes has improved }\end{array}$ & $91(91.0)$ & $88(97.8)$ & $63(98.4)$ & $\begin{array}{c}122 \\
(95.3)\end{array}$ & $364(95.3)$ \\
\hline $\begin{array}{l}\text { My approach to diagnosis and management of } \\
\text { Asthma has improved }\end{array}$ & $81(81.0)$ & $86(95.6)$ & $61(95.3)$ & $119(93.0)$ & $347(90.8)$ \\
\hline $\begin{array}{l}\text { I am supported to use the skills I have } \\
\text { acquired in managing Asthma and diabetes }\end{array}$ & $77(77.0)$ & $77(85.6)$ & $44(68.8)$ & $94(73.4)$ & $292(76.4)$ \\
\hline $\begin{array}{l}\text { I feel confident while managing my diabetic } \\
\text { and asthma patients }\end{array}$ & $90(90.0)$ & $84(93.3)$ & $62(96.9)$ & $119(93.0)$ & $355(92.9)$ \\
\hline $\begin{array}{l}\text { I do not require further training to be effective } \\
\text { in the diagnosis and management of Asthma } \\
\text { and diabetes }\end{array}$ & $17(17.0)$ & $10(11.1)$ & $18(28.1)$ & $24(18.8)$ & $69(18.1)$ \\
\hline $\begin{array}{l}\text { The way I managed asthmatic and diabetic } \\
\text { patients before the training has not changed }\end{array}$ & $12(12.0)$ & $13(14.4)$ & $13(20.3)$ & $36(28.1)$ & $74(19.4)$ \\
\hline $\begin{array}{l}\text { There are no incentives to use the acquired } \\
\text { skills from the training. }\end{array}$ & $51(51.0)$ & $40(44.4)$ & $37(57.8)$ & $70(54.7)$ & $198(51.8)$ \\
\hline $\begin{array}{l}\text { There are systems in place to support } \\
\text { application of skills gained from training }\end{array}$ & $68(68.0)$ & $66(73.3)$ & $31(48.4)$ & $84(65.6)$ & $249(65.2)$ \\
\hline
\end{tabular}

\section{Table 7: Merits and demerits of the different training approaches}

\section{Method of Merit Training

\begin{tabular}{|l|l}
$\begin{array}{l}\text { Face to } \\
\text { face }\end{array}$ & $\begin{array}{l}\text { Provides opportunity for practical activities } \\
\text { Provides human interaction enhancing learning } \\
\text { Enables learning from experiences of others }\end{array}$ \\
\hline E-learning & $\begin{array}{l}\text { Ability to reach many people through two main } \\
\text { ways: } \\
\text { Instant access to information to many people at } \\
\text { same time } \\
\text {-access to downloaded information at point of } \\
\text { services for updates and refreshes }\end{array}$ \\
\hline
\end{tabular}

M-learning Ability to reach out many people and flexibility in learning process

\section{Demerits}

Costs of face to face is high compared to the other types

\section{Lack of access to reliable internet and} power

Need for intermittent support through face to face to enhance learning

Requires availability of a phone that can support internet

Content need development in a variety of languages 


\section{Supplementary Files}

This is a list of supplementary files associated with this preprint. Click to download.

- Appendix1ProgramPillars.docx 